\title{
RANCANG BANGUN SISTEM ELECTRONIC COMPLAINT SISWA BERBASIS WEB Di SMA NEGERI 3 PANDEGLANG MENGGUNAKAN METODE WATERFALL
}

\author{
Muhaimin Hasanudin; Indrianto; Denny Andwiyan \\ STMIK Raharja Tangerang \\ Sekolah Tinggi Teknik PLN Jakarta \\ mhasanudin17@gmail.com, indrianto_basayev@yahoo.com, dennyandwiyan@gmail.com
}

\begin{abstract}
Abstrak
Didalam perkembangan teknologi informasi sering sekali orang menginginkan tantangan kecepatan, ketepatan, dan kemudahan di dalam akses suatu sistem informasi yang harus dapat dipenuhi dengan baik. Sistem penyampaian keluhan di SMA Negeri 3 Pandeglang masih kurang efektif yaitu siswa melakukan pengaduan keluhan masih menggunakan cara pencatatan di kertas atau siswa datang langsung ke ruangan guru dalam menyampaikan keluhan pada wali kelas. Hal ini menyebabkan ada kendala yang dihadapi oleh wali kelas dimana terjadi kehilangan kerusakan pada kertas pengaduan keluhan sehingga pengaduan keluhan tidak tersampaikan pada wali kelas dan kepala sekolah. Atas dasar permasalahan diatas, peneliti membuat suatu sistem berbasis web diharapkan dapat membantu siswa dalam menyampaikan keluhan dan memudahkan wali kelas, kepala sekolah dan guru dalam menangani keluhan siswa yang berkelanjutan secara efektif. Dalam perancangan sistem menggunakan UML (Unified Modelling Language) dan menggunakan metode waterfall ini mengusulkan sebuah pendekatan kepada pengembangan software yang sistematik dan sekuensial yang mulai dari tingkat kemajuan sistem pada seluruh analisis, desain, koding, pengujian dan pemeliharaan.
\end{abstract}

Kata Kunci: keluhan siswa, siswa, uml, metode waterfall

\begin{abstract}
In the development of information technology very often people want the challenge of speed, accuracy, and ease of access in an information system that must be met well. The grievance system in SMA Negeri 3 Pandeglang is still less effective ie the students complaint complaint still use the way of recording in the paper or the students come directly to the teacher room in complaint to the homeroom teacher. This causes obstacles faced by the guardian of the class where there is a loss of damage on the complaint complaint paper so that complaints complaints are not conveyed to the homeroom teacher and principal. On the basis of the above problems, researchers create a web-based system is expected to help students in complaints and facilitate homeroom teachers, principals and teachers in handling sustainability of student complaints effectively. In designing the system using UML (Unified Modeling Language) and using waterfall method it proposes an approach to systematic and sequential software development starting from the system advance level on all analysis, design, coding, testing and maintenance.
\end{abstract}

Key Words : complaints of students, students, uml, waterfall method

\section{PENDAHULUAN}

\subsection{LATAR BELAKANG}

Didalam perkembangan teknologi informasi yang biasa orang menyebut IT ( Information Technology ) sering sekali orang menginginkan tantangan kecepatan, ketepatan, dan kemudahan di dalam akses suatu sistem informasi yang harus dapat dipenuhi dengan baik. Hal tersebut tidak terlepas dari peran sumber daya manusia untuk mengembangkan dan memanfaatkan perkembangan teknologi yang semakin pesat. Karena apabila perkembangan teknologi yang semakin pesat ini tidak disertai dengan kemauan dan keinginan, maka perkembangan teknologi tersebut akan menjadi sia - sia.

Complaint atau keluhan itu sebenarnya merupakan bagian dari bentuk komunikasi sebuah informasi tentang ketidaksesuaian. Complaint atau keluhan sebenarnya dibutuhkan, karena complaint akan menghasilkan sebuah informasi. Entah informasi positif atau informasi negatif. Bahkan complaint merupakan sebuah komunikasi aktif yang bisa menjurus kedalam sebuah interaksi.

Pengaduan siswa merupakan suatu partisipasi siswa agar penyedia layanan di sekolah yang dapat menampung keluhan siswa. Hal tersebut dilakukan dengan tujuan agar pihak terkait dapat memperhatikan apa yang menjadi kebutuhan siswa sehingga tercipta pelayanan yang baik, dengan adanya sistem electronic complaint memudahkan para siswa untuk menyalurkan kritik dan saran terhadap pelayanan sekolah yang kurang memuaskan.

\subsection{Tujuan Penelitian} berikut:

Tujuan penelitian diantaranya adalah sebagai

1. Merancang atau membangun sebuah sistem komplain siswa di SMA Negeri 3 Pandeglang. 
2. Membuat system yang dapat menyajikan informasi yang tepat, akurat, efektif, serta efisien

\subsection{Manfaat Penelitian} berikut:

Maksud penelitian diantaranya adalah sebagai

1. Memudahkan pendataan komplain siswa bagi staff BP/BK agar lebih cepat dan tepat.

2. Membantu dalam pembuatan laporan yang lebih akurat, cepat dan efisien.

\subsection{Rumusan Masalah}

Perumusan masalah merupakan penegas dari apa menjadi inti penelitian. Sesuai latar belakang tersebut, maka perumusan masalah yang ada di dalam penelitian ini adalah:

1. Bagaimanakah sistem komplain yang berjalan di SMA Negeri 3 Pandeglang ?

2. Apakah kendala yang dihadapi pada sistem komplain di SMA Negeri 3 Pandeglang ?

3. Sistem komplain siswa seperti apakah yang diperlukan di SMA Negeri 3 Pandeglang ?

\section{METODOLOGI PENELITIAN}

Untuk metode penelitian yang digunakan, adalah metode SDLC (System Development Life Cycle) jenis waterfall ini cocok untuk menggambarkan sistem. Model waterfall atau sering disebut model sekuensial linier atau alur hidup klasik (Pressman, 2001). Model air terjun menyediakan pendekatan alur hidup perangkat lunak secara sekuensial atau terurut dimulai dari analisis, desain, pengodean, pengujian, dan tahap pemeliharaan seperti yang disajikan pada gambar 3.2:

Langkah-langkah model waterfall adalah sebagai berikut:

1. Analisis kebutuhan perangkat lunak, Proses pengumpulan kebutuhan dilakukan secara intensif untuk mespesifikasikan kebutuhan perangkat lunak agar dapat dipahami perangkat lunak seperti apa yang dibutuhkan oleh user.Spesifikasi kebutuhan perangkat lunak pada tahap ini perlu untuk didokumentasikan.

2. Desain, Desain perangkat lunak adalah proses multi langkah yang fokus pada desain pembuatan program perangkat lunak termasuk struktur data, arsitektur perangkat lunak, repesentasi antarmuka, dan prosedur pengodean. Tahap ini mentraslasikan kebutuhan perangkat lunak dari tahap analisis kebutuhan ke representasi desain agar dapat diimplementasikan menjadi program pada tahap selanjutnya. Desain perangkat lunak yang dihasilkan pada tahap ini juga perlu didokumentasikan.

3. Pembuatan kode program, Desain harus ditranslasikan ke dalam program perangkat lunak. Hasil dari tahap ini adalah program komputer sesuai dengan desain yang telah dibuat pada tahap desain.

4. Pengujian, Pengujian dilakukan dengan mengetahui pespektif user terhadap kualitas perangkat lunak berdasakan ISO/IEC 9126, jadi disini tidak menggunakan black box/white box testing.

5. Pendukung (support) atau Pemeliharaan (maintenance), Tidak menutup kemungkinan sebuah perangkat lunak mengalami perubahan ketika sudah dikirimkan ke user. Perubahan bisa terjadi karena adanya kesalahan yang muncul dan tidak terdeteksi saat pengujian atau perangkat lunak harus beradaptasi dengan lingkungan baru.

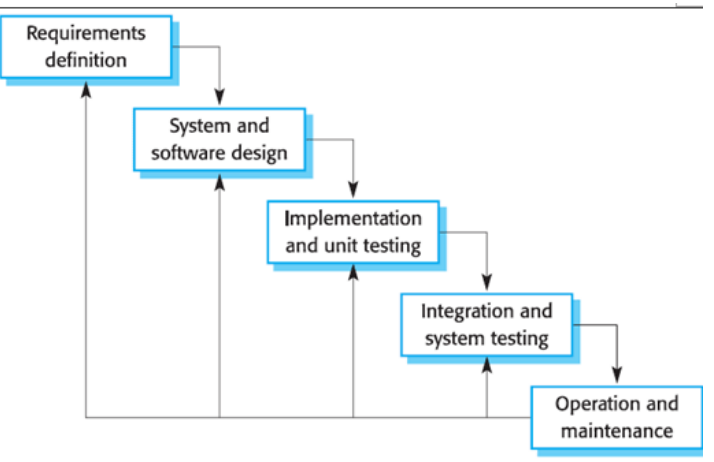

Gambar 2.1. Model Waterfall

\section{PERANCANGAN SISTEM USULAN}

\subsection{Rancangan Sistem Usulan Keluhan Siswa}

Untuk menganalisa dan merancang sistem yang diusulkan, pada penelitian ini digunakan program Visual Paradigm for UML, untuk menggambarkan Use Case Diagram, Activity diagram, Sequence Diagram dan Class Diagram

\subsection{Activity Diagram}

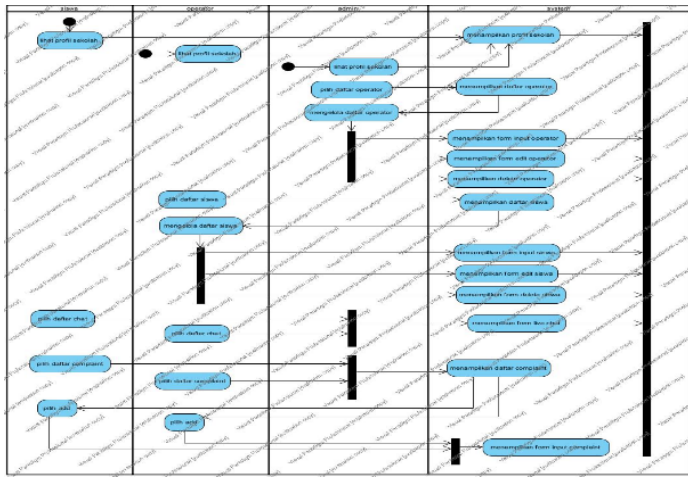

Gambar 3.1 Activity Diagram Keluhan Siswa Yang Diusulkan

Berdasarkan gambar 3.1 Activity Diagram yang diusulkan Keluhan Siswa terdapat :

a. Tiga (3) Initial Node, objek yang diawali.

b. Dua puluh lima (25) action yaitu : lihat profil sekolah, lihat profil sekolah, lihat profil sekolah, menampilkan profil sekolah, pilih daftar operator, menampilkan daftar operator, mengelola daftar operator, menampilkan form input operator, menampilkan form edit operator, menampilkan form delete operator, pilih daftar siswa, menampilkan daftar siswa, 
mengelola daftar siswa, menampilkan form input siswa, menampilkan form edit siswa, menampilan for delete siswa, pilih daftar chat, pilih daftar chat, menampilkan form live chat, pilih daftar complaint, pilih daftar complaint, menampilkan daftar complaint, pilih add, pilih add, menampilkan form input complaint

c. Satu (1) (Satu) Decision Node, untuk membuat keputusan

\subsection{Use Case Diagram}

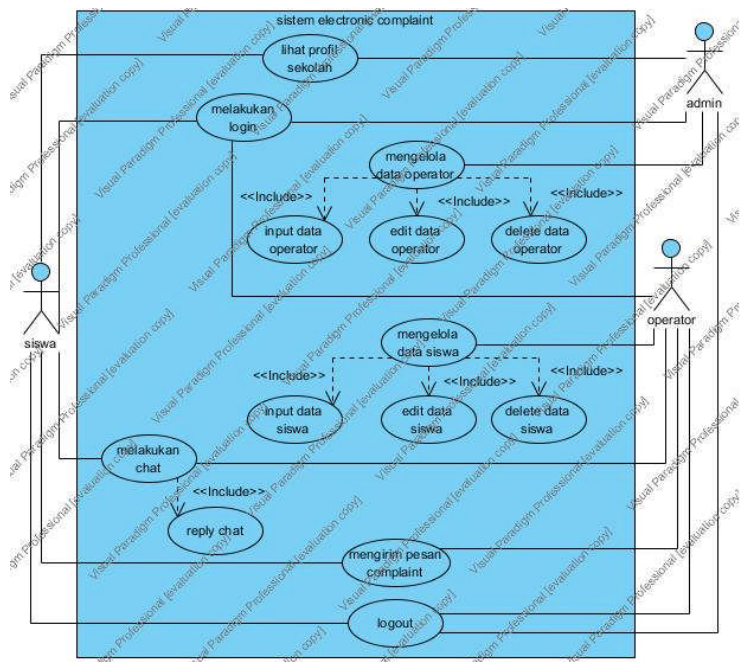

Gambar 3.2 Use Case Diagram Keluhan Siswa Yang Diusulkan

Berdasarkan Gambar 3.2. Use Case Diagram yang diusulkan terdapat :

a. 1 (Satu) Sistem yang mencakup seluruh kegiatan sistem pada keluhan siswa.

b. 3 (Tiga) Actor yang melakukan kegiatan, diantaranya : Siswa, Operator Dan Admin.

c. 14 (Empatbelas) Use Case yang dilakukan diantaranya : lihat profil sekolah, melakukan login, mengelola data operator, edit data operator, delete data operator, mengelola data siswa, input data siswa, edit data siswa, delete darta siswa, melakukan chat, reply chat, mengirim pesan complaint, logout.

Adapun prosedur skenario dari use case Diagram yang diusulkan yaitu sebagai berikut :

1. Prosedur lihat profil sekolah.

a. Use Case : lihat profil sekolah.

b. Aktor : Siswa, Admin, Operator

c. Skenario :

1) Aktor membuka aplikasi sistem Electronic Complaint.

2) Sistem menampilkan halaman profil sekolah.

3) Aktor melakukan aktifitas lain atau menutup aplikasi.

2. Prosedur melakukan login.

a. Use Case : Melakukan Login.

b. Aktor : Siswa, Admin, Operator

c. Skenario :

1) Aktor melakukan login.

2) Login admin menampilkan mengelola data operator.
3) Login operator menampilkan mengelola data siswa.

4) Login siswa menampilkan melakukan chat.

3. Prosedur mengelola data operator.

a. Use Case : Mengelola data operator.

b. Aktor: Admin

c. Skenario :

1) Aktor melakukan login.

2) Aktor menampilkan mengelola data operator.

3) Aktor input data operator, edit data operator dan delete data operator.

4. Prosedur mengelola data siswa.

a. Use Case : Mengelola data siswa.

b. Aktor: Operator

c. Skenario :

1) Aktor melakukan login.

2) Aktor menampilkan mengelola data siswa.

3) Aktor input data siswa, edit data siswa, dan delete data siswa.

5. Prosedur melakukan chat.

a. Use Case : Melakukan chat.

b. Aktor : Siswa, Operator

c. Skenario :

1) Aktor melakukan login.

2) Siswa melakukan chat

3) Operator reply chat

6. Prosedur mengirim pesan complaint.

a. Use Case : Mengirim pesan complaint.

b. Aktor : Siswa, Operator

c. Skenario :

1) Aktor melakukan login.

2) Siswa mengirim pesan complaint saat operator offline.

3) Operator menerima pesan siswa saat online.

7. Prosedur logout

a. Use Case : Logout.

b. Aktor : Siswa, Operator, Admin

c. Skenario :

1) Jika aktor sudah selesai mengoperasikan program tersebut dan ingin keluar dari program maka harus melalui menu Logout

\subsection{Sequence Diagram}

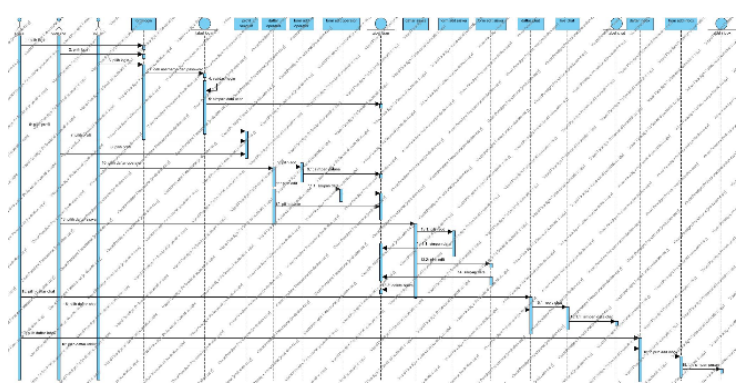

Gambar 3.3 Sequence Diagram Keluhan Siswa Yang Diusulkan

Berdasarkan gambar 3.3 Sequence Diagram yang diusulkan terdapat :

a. 3 (Tiga) Actor yang melakukan kegiatan, yaitu Siswa, Admin, Operator 
b. 12 (duabelas) Lifeline yang saling berinteraksi yaitu : form login, profil sekolah, daftar operator, form add operator, form edit operator, daftar user, form add user, form edit user, daftar chat, live chat, daftar inbox, form add inbox

c. 28 (Dua puluh sembilan) Message yaitu menspesifikasikan dari komunikasi antar objek yang memuat informasi-informasi tentang aktifitas yang terjadi. Kegiatan yang biasa dilakukan oleh actor-actor

\subsection{Class Diagram}

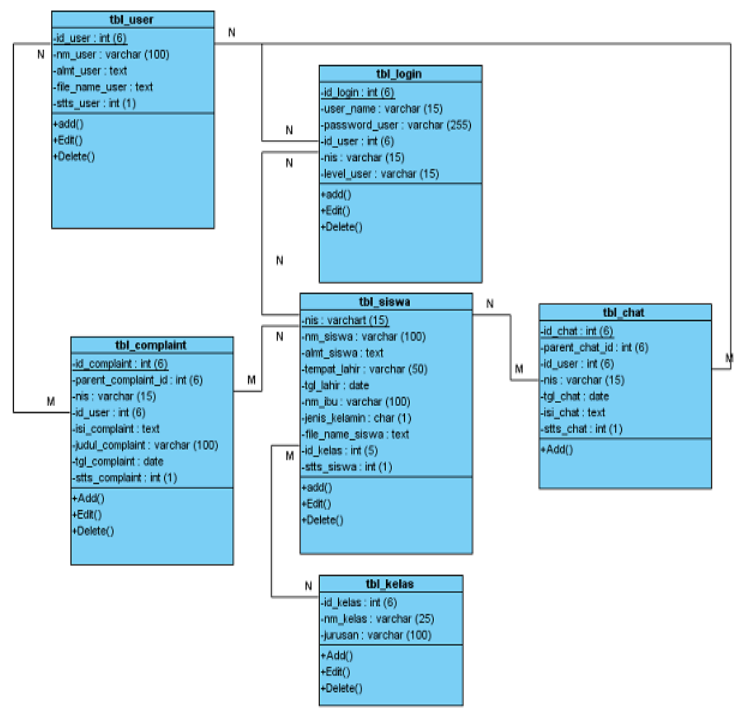

Gambar 3.4 Class Diagram Keluhan Siswa Yang Diusulkan

Berdasarkan Gambar 3.4 Class Diagram yang di usulkan terdapat :

a. 6 Class dari objek-objek yang berbagi antribut serta operasi diantaranya: tabel_login, tabel_user, tabel_complaint, tabel_siswa, tabel_kelas, tabel_chat.

b. 7 association, hubungan antar objek satu dengan objek lainnya yang mempunyai nilai.

\subsection{Perbedaan Prosedur}

Berikut ini adalah perbedaan prosedur antara sistem yang berjalan dan sistem usulan yang ditunjukkan pada tabel 3.1 :

Tabel 3.1. Perbedaan prosedur antara sistem yang berjalan dan sistem usulan

\begin{tabular}{|cl|cl|}
\hline \multicolumn{2}{|c|}{ Sistem Yang Berjalan } & \multicolumn{2}{c|}{ Sistem Yang Diusulkan } \\
\hline 1. & Sistem Manual & 1. & $\begin{array}{l}\text { Sistem } \\
\text { Komputerisasi }\end{array}$ \\
\hline 2. & $\begin{array}{l}\text { laporan keluhan } \\
\text { masih menggunakan } \\
\text { kertas }\end{array}$ & 2. & $\begin{array}{l}\text { laporan dapat } \\
\text { langsung di print }\end{array}$ \\
\hline 3. & Informasi terbatas & 3. & $\begin{array}{l}\text { Informasi dapat } \\
\text { diperbarui dengan } \\
\text { mudah dan cepat }\end{array}$ \\
\hline 4. & $\begin{array}{l}\text { Tidak ada } \\
\text { pengamanan data }\end{array}$ & 4. & $\begin{array}{l}\text { Sistem } \\
\text { pengamanan sudah } \\
\text { tersedia }\end{array}$ \\
\hline
\end{tabular}

Dapat disimpulkan bahwa dengan adanya sistem yang diusulkan dapat membantu siswa dan operator dalam mengenai sebuah keluhan, dan informasi yang dihasilkan pun lebih akurat, sehingga dapat di ketahui apa saja yang sering kena complaint.

\section{IMPLEMENTASI PROGRAM}

\subsection{Tampilan Halaman Home}

Pada menu home memberikan tampilan dengan fitur - fitur yang admin dapat tampilkan.

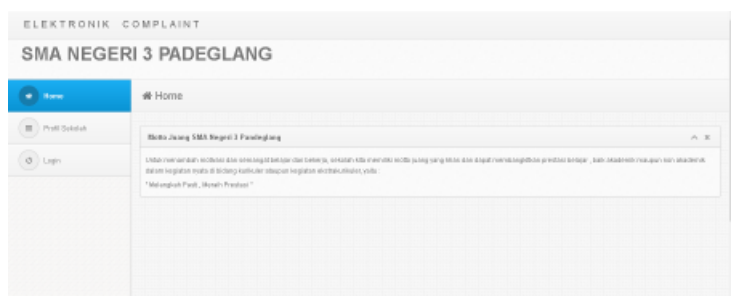

Gambar 4.1. Tampilan Halaman Home

\subsection{Tampilan Halaman Profil Sekolah}

Pada menu profile sekolah memberikan tampilan dengan fitur - fitur dan content tentang sejarah sekolah, misi dan misi serta tujuan sekolah.

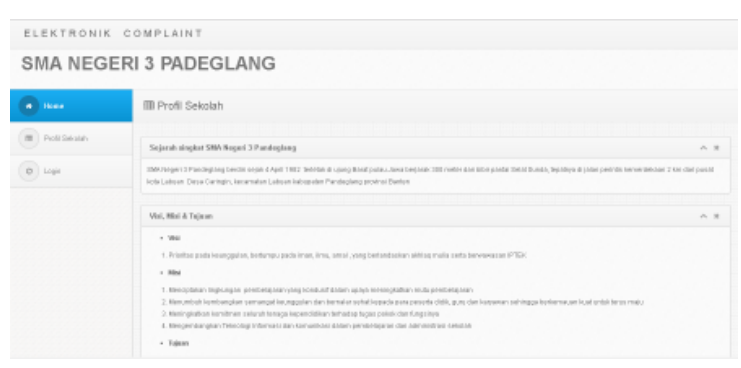

Gambar 4.2. Tampilan Halaman Profile Sekolah

\subsection{Tampilan Halaman login}

Halaman Login ini merupakan sebuah halaman untuk memasukkan identitas seperti username dan password yang benar. Fungsi utama halaman login adalah untuk melindungi sistem.

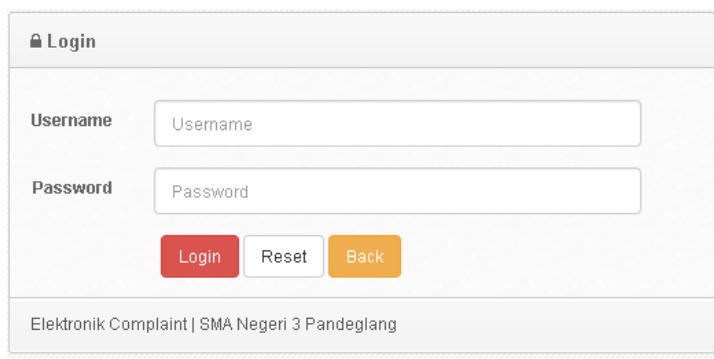

Gambar 4.3. Tampilan Halaman Login

\subsection{Tampilan Halaman Daftar Operator}

Pada tampilan menu daftar oprator ini terdapat tampilan tabel yang berisi data data nama operator dan level status yang telah di input oleh admin. 


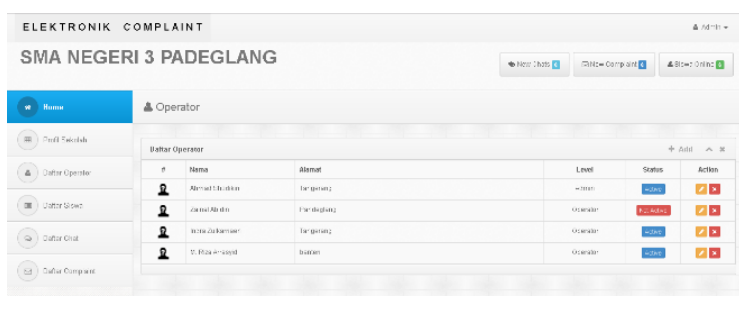

Gambar 4.4. Halaman Operator

\subsection{Form Input Operator}

Halaman "Form input operator" ini merupakan halaman yang bertujuan untuk menginput daftar operator. Admin dapat menginput operator di halaman ini.

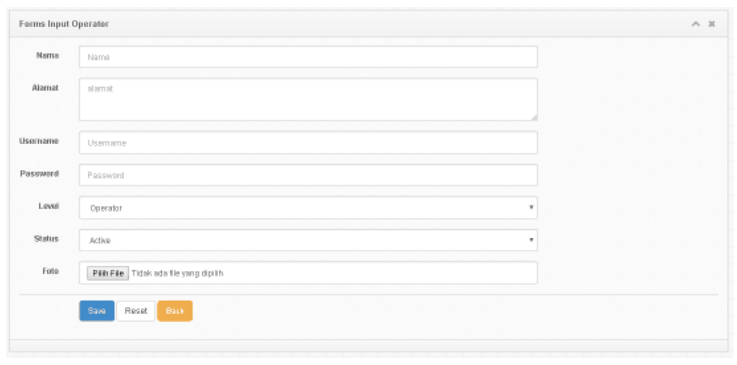

Gambar 4.5. Form Input Operator

\subsection{Form Daftar Siswa}

Pada tampilan menu daftar siswa ini terdapat tampilan tabel yang berisi data data nama siswa, nis, alamat, kelas dan jurusan yang telah di input oleh operator.

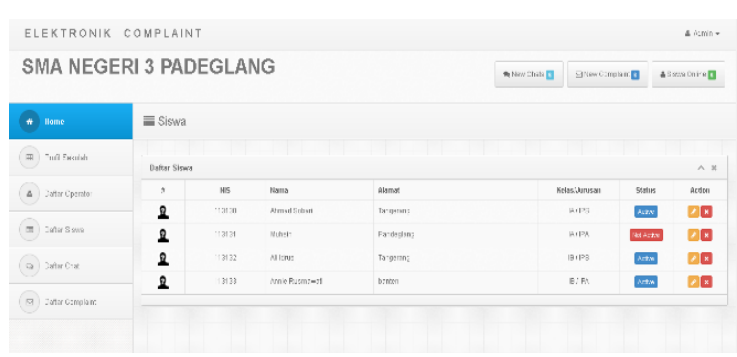

Gambar 4.6. Form Daftar Siswa

\subsection{Halaman Form Input Siswa}

Halaman "Form input siswa" ini merupakan halaman yang bertujuan untuk menginput daftar siswa. Operator dapat menginput operator di halaman ini.

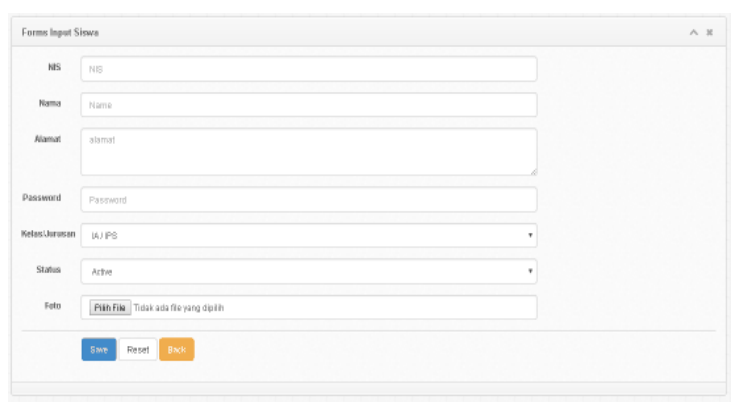

Gambar 4.7. Form Input Siswa

\subsection{Halaman Daftar Chat}

Halaman "Daftar Chat" ini merupakan halaman untuk melihat history chat antar operator dan siswa saling berkomunikasi.

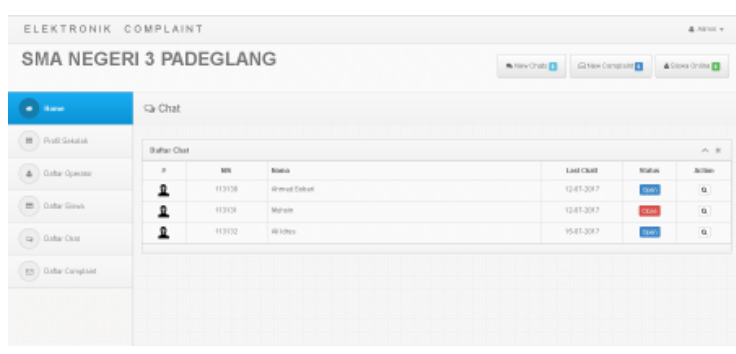

Gambar 4.8. Form Daftar Chat

\subsection{Halaman Live Chat}

Halaman "Live Chat" ini merupakan halaman untuk live chat antara siswa dengan operator

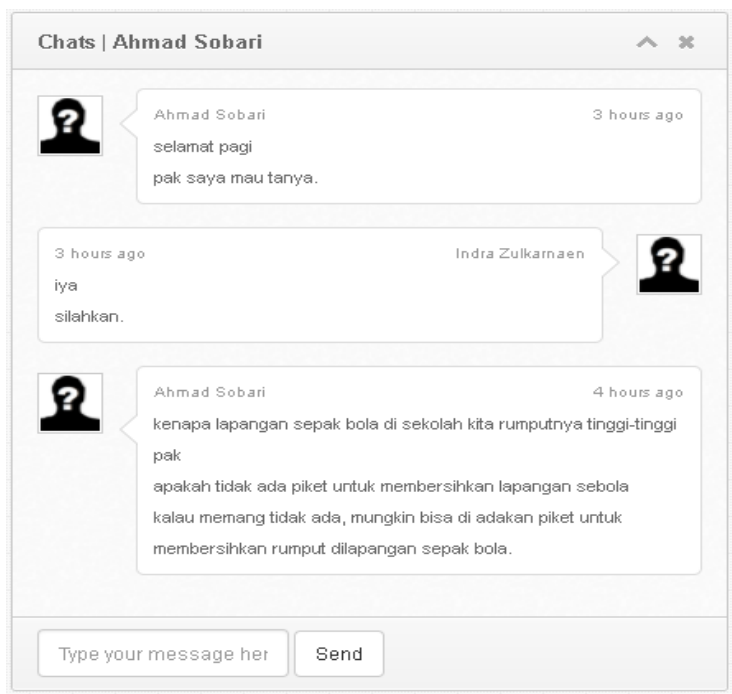

Gambar 4.9. Form Live Chat

\subsection{Halaman Daftar Complaint}

Halaman "Daftar Complaint" ini merupakan halaman untuk mengirim pesan keluhan dan status keluhan.

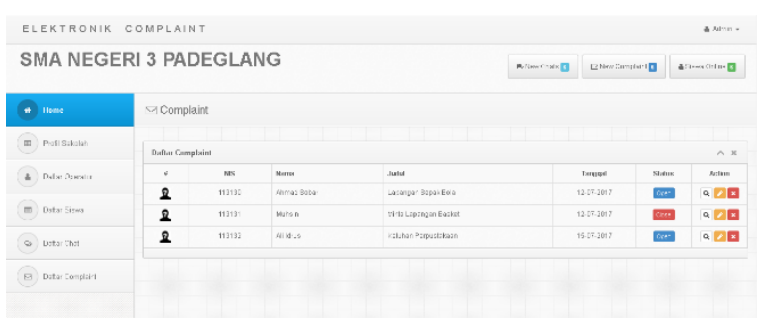

Gambar 4.10. Form Daftar Complain

\section{PENUTUP}

\subsection{Kesimpulan}

Berdasarkan analisa yang di lakukan di SMA Negeri 3 Pandeglang dapat disimpulkan bahwa :

1. Prosedur komplain siswa di SMA Negeri 3 Pandeglang ditangani oleh Guru BP/BK dan 
masih dilakukan secara konvensional dengan proses pencatatannya masih menggunakan buku, sehingga sering terjadi kehilangan data keluhan atau komplain siswa dan proses pengolahan data belum berjalan maksimal dikarenakan belum terkomputerisasi. Dampak lain adalah memakan waktu lama informasi keluhan.

2. Kendala sistem yang berjalan saat ini adalah sistem yang berjalan saat ini masih manual, sehingga siswa yang ingin komplain harus ke ruangan guru ada di sekolah secara langsung sehingga tidak efektif dan efesien.

3. Untuk membuat sistem dibutuhkan suatu sistem berbasis web. SMA Negeri 3 Pandeglang membutuhkan sistem yang lebih efektif dan efisien dalam hal penyampaian keluhan siswa tersampaikan dan dibutuhkan juga media penyimpanan data hasil keluhan siswa, sehingga lebih akurat dan mampu mengatasi permasalahan yang ada.

\subsection{Saran}

Setelah memberikan kesimpulan mengenai sistem electronic complaint siswa yang sedang berjalan dan sistem yang dibangun, maka agar mencapai hasil optimal untuk mengatasi permasalahan yang ada, maka saran dan pendapat penulis adalah sebagai berikut

1. Sistem diharapkan dapat dikembangkan lebih baik lagi yang mampu mendeteksi pertanyaan yang sama dan kemudian sistem yang menjawabnya secara otomatis seperti sistem pakar, KMS.

2. Dibuatkan menu laporan guna untuk melihat kinerja dari masing masing operator.

3. Enkripsi saat mengiriman pesan dan live chat sangat di perlukan untuk sebuah pengembangan selanjutnya guna untuk meningkatkan keamanan sistem.

\section{DAFTAR PUSTAKA}

1. Fajarita, Lusi 2015. Analisa Dan Perancangan Sistem Informasi Penanganan Keluhan Pelanggan Pada Pt. Paron Indonesia.

2. Lee, SungukUnified Modeling Language (UML) for Database Systems and Computer Applications. International Journal of Database Theory and Application. Vol.5 No.1.

3. O'Brien, James A. 2011. Management Information Systems, 10th Edition. McGrawHill/ Irwin, New York.

4. Saputra, Gerizky 2016. Pengembangan Sistem Penanganan Keluhan berbasis Web (Studi Kasus: Fakultas Teknik Universitas Muhammadiyah Yogyakarta).

5. Taufiq, Rohman 2013. "Analisis dan Desain Sistem Informasi”. Yogyakarta: Graha IImu

6. Widodo, Prabowo 2011. "Menggunakan UML". Bandung: Institut Teknologi Bandung.

7. Wiyanto 2011. Pengelolaan Komplain (Keluhan) Masyarakat Dalam Mewujudkan Tata Pamong Yang Baik (Good Governance) Di Kota Semarang.

8. Pressman, Roger, S 2011. Software Engineering: A Practitioner's Approach,Fifth Ed. New York,McGraw-Hill Book Company 